\title{
CREATING AND IMPROVING EDUCATIONAL MATERIALS: AN APPROACH BASED ON CROWDSOURCING
}

\author{
M.C. Suárez-Figueroa, E. Ruckhaus, O. Corcho, M. Molina, E. Serrano, \\ D. Zanardini
}

Universidad Politécnica de Madrid (SPAIN)

\begin{abstract}
One way of increasing the quantity and quality of educational materials that are available on-line is to apply collaborative and crowdsourcing techniques during the production process. The idea of involving groups of learners working together to solve a problem, to complete a task, or to create a product is an educational approach to teach and learn called Collaborative Learning $(\mathrm{CL})$. One way of applying the $\mathrm{CL}$ approach is by using a collaborative authoring platform such as SlideWiki. This paper presents a crowdsourced-based approach for involving students in the creation and improvement of educational materials using the SlideWiki platform.
\end{abstract}

Keywords: Crowdsourcing, Educational Material, Collaborative Learning.

\section{INTRODUCTION}

Open Educational Resources in general and OpenCourseWare (OCW) in particular can be shared and reused, thus fostering knowledge interchange among teachers and learners. Currently, there are different OCW platforms that open new horizons for knowledge sharing and e-learning by reaching learners beyond the constraints of traditional learning systems. However, there is a lack of on-line educational content due to the fact that their creation and maintenance is tedious, time-consuming and expensive.

Costs associated to the creation of educational materials as well as quality of those materials can be improved by applying collaborative techniques during the production process [1]. Collaborative authoring has improved the efficiency, effectiveness, quality and timeliness of content creation in different domains such as text, geospatial content, and software code. Therefore it is to be expected that in the educational domain, a crowdsourcing approach helps to increase the quantity and quality of OCW.

The idea of involving groups of learners working together to solve a problem, to complete a task, or to create a product is an educational approach to teaching and learning called Collaborative Learning $(\mathrm{CL})$ [2]. One way of applying the $\mathrm{CL}$ approach is by using a collaborative authoring platform such as the SlideWiki platform ${ }^{\prime}$. The SlideWiki platform allows users to collaboratively create and maintain OCW (e.g. slide presentations) in a crowdsourcing and on-line fashion. This platform is part of the socalled Web 2.0 technologies in which users can be active contributors rather than just passive observers. This collective intelligence can be used for both instructors and students to create educational materials that can have great value [3].

SlideWiki [4] is a crowdsourcing platform that aims to rethink the creation and sharing of knowledge by providing an environment where authors can collaborate, reuse, adapt and share slide content for educational purposes. The SlideWiki platform, which follows a similar approach to Wikipedia, is being developed as part of a European project of the same name ${ }^{2}$.

The SlideWiki platform decomposes learning materials into fine-grained artifacts (e.g., slides and decks) that are organized into tree structures; such artifacts are described semantically using ontologies. Educational artifacts (e.g., slides and decks) are internally represented using HTML, but import and export to widely-used presentation formats (e.g., PPTX) are available.

In this paper we present a novel approach based on crowdsourcing to involve students in the creation and improvement of educational materials that serve for the study and/or self-learning of knowledge

\footnotetext{
${ }^{1}$ http://slidewiki.org/

${ }^{2}$ http://slidewiki.eu
} 
included in university subjects. The creation of educational materials following this approach allows the development of an extensive repository of educational content that can be shared and reused within the educational community. In order to validate our proposal, the approach will be applied in different courses.

This paper is organized as follows: Section 2 is devoted to explain our crowdsourced-based approach; Section 3 presents how the evaluation of the approach is performed as well as preliminary results; and Section 4 briefly shows some conclusions and future work.

\section{METHODOLOGY: OUR CROWDSOURCED-BASED APPROACH}

The general idea of our educational method is based on the execution of a set of learning activities in which students can actively participate to create and improve educational materials in a collaborative authoring platform. Our educational approach is based on the execution of the following processes:

1 Design of the learning activities to be carried out and their creation in the collaborative authoring platform

2 Selection of the educational materials needed for the activities and their incorporation in the collaborative authoring platform

3 Design and creation of questionnaires to gather the opinions of the students

4 Completion of the proposed learning and educational activities

5 Gathering of students opinions

6 Analysis of the data collected in the questionnaires

7 Proposal of changes in the educational approach

In our approach, the use of SlideWiki as a collaborative authoring platform allows the active participation of students in creating and improving educational materials. The platform allows users to create and maintain slide presentations in a crowdsourcing and on-line fashion, and aims to promote the consolidation of prior knowledge, to avoid duplication of efforts in the creation of educational material (promoting the reuse of existing materials), as well as to share good practices.

The SlideWiki platform can be seen as a Web 2.0 technology in which users can be active contributors rather than just passive observers. The materials developed by active users may have significant innovation and economic value. This collective intelligence can be used for both instructors and students to create educational materials that can have great value.

The design of the learning activities to be carried out in our approach is based on a catalog of activities $^{3}$, created as part of the European SlideWiki project. This catalog serves as a support to teachers during the preparation of the tasks and assignments that students must complete in the courses. Our proposal focuses on a set of 4 educational activities that are explained in Section 2.1.

The crowdsourcing approach presented in this paper will be applied in diverse subjects belonging to the Artificial Intelligence area in different university courses. To evaluate the proposed approach, we will (a) gather students opinions via questionnaires, (b) apply learning analytics techniques to compare subject results along different courses, and (c) analyze official surveys on the teaching activity.

\subsection{Educational Activities in our Approach}

Our proposal focuses on the following educational activities:

- To provide comments and feedback for a selection of educational content. The goal here is to improve the clarity of the slides provided by teachers, to find errors, to explain the concepts in ways closer to the students vocabulary, and/or to propose suggestions to the theoretical and practical content.

- To summarize in 5 points. The idea here is to ask students to summarize in 5 sentences a certain topic relevant to a particular subject. In addition to the summary, students must relate what they have learned in that topic to what they have learned in other subjects.

${ }^{3}$ https://slidewiki.org/deck/108357/learning-activity-catalogue-for-students-and-participants 
- To create a collection of questions for self-evaluation. This activity consists in the preparation of a set of questions together with their possible answers (including the correct answer(s)), that can be used for self-evaluation of the subject.

- To create solutions for proposed exercises. The idea here is to compile solutions to exercises in a collaborative way. Possible exercises to be used in this activity may consist of finding errors in given solutions, classifying elements, completing incomplete and/or erroneous sentences, among others.

\subsection{Use Cases in our Approach}

Our approach is being implemented in a total of six subjects of different educational levels (undergraduate and master's degrees) and in diverse courses. All the subjects belong to the Artificial Intelligence area and involve different teachers and different natural languages. Thanks to this diversity of educational scenarios we will be able to analyze whether the educational level and/or the course taken by the students has some implication in the degree of motivation and participation of students in this type of innovative educational activities.

Table 1 shows the set of subjects divided according the educational level (Bachelor and Master). For each subject, we provide information about the course, the period in which the educational activities are scheduled, and the subset of learning activities that are planned to be performed.

Table 1. Use Cases in Bachelor and Master

\begin{tabular}{|c|c|c|c|c|}
\hline $\begin{array}{l}\text { EDUCATIONAL } \\
\text { LEVEL }\end{array}$ & SUBJECT & COURSE & PERIOD & PLANNED EDUCATIONAL ACTIVITIES \\
\hline \multirow{4}{*}{ Bachelor } & $\begin{array}{c}\text { Logic } \\
\text { (Spanish) }\end{array}$ & $\begin{array}{l}\text { First } \\
\text { Course }\end{array}$ & $\begin{array}{l}\text { September- } \\
\text { November } \\
2018\end{array}$ & $\begin{array}{l}\text { - To provide feedback to a selection of } \\
\text { educational content } \\
\text { - To summarize in } 5 \text { points } \\
\text { - To create questions for self-evaluation } \\
\text { - To create solutions for proposed exercises } \\
\text { proposed }\end{array}$ \\
\hline & $\begin{array}{l}\text { Artificial Intelligence } \\
\text { (Spanish) }\end{array}$ & $\begin{array}{l}\text { Third } \\
\text { Course }\end{array}$ & $\begin{array}{c}\text { September- } \\
\text { October } 2018\end{array}$ & $\begin{array}{l}\text { - To provide feedback to a selection of } \\
\text { educational content } \\
\text { - To summarize in } 5 \text { points. }\end{array}$ \\
\hline & $\begin{array}{l}\text { Logic Programming } \\
\text { (Spanish) }\end{array}$ & $\begin{array}{l}\text { Third } \\
\text { Course }\end{array}$ & $\begin{array}{c}\text { March-May } \\
2018\end{array}$ & - To create questions for self-evaluation \\
\hline & $\begin{array}{l}\text { Semantic Web and } \\
\text { Linked Data } \\
\text { (English) }\end{array}$ & $\begin{array}{l}\text { Fourth } \\
\text { Course }\end{array}$ & $\begin{array}{l}\text { September- } \\
\text { November } \\
2018\end{array}$ & - To create questions for self-evaluation \\
\hline \multirow[b]{2}{*}{ Master } & $\begin{array}{l}\text { Intelligent Systems } \\
\text { (English) }\end{array}$ & $\begin{array}{c}\text { First } \\
\text { Semester }\end{array}$ & $\begin{array}{l}\text { September- } \\
\text { November } \\
2018\end{array}$ & - To create questions for self-evaluation \\
\hline & $\begin{array}{l}\text { Information } \\
\text { Retrieval, } \\
\text { Extraction and } \\
\text { Integration } \\
\text { (English) }\end{array}$ & $\begin{array}{l}\text { Second } \\
\text { Semester }\end{array}$ & $\begin{array}{l}\text { April-May } \\
2018\end{array}$ & - To summarize in 5 points \\
\hline
\end{tabular}

\section{EVALUATION}

One of the processes in our crowdsourcing-based approach is the design and creation of questionnaires to gather the opinions of the students. The purpose of these surveys is to know how useful and interesting are the learning activities performed in a collaboratively fashion during the courses. The feedback received via the questionnaires serves to evaluate the impact of the approach as well as to improve it. 
The survey we have created is composed of three parts as shown in Figure 1: (a) one question about the learning activities performed using SlideWiki; (b) three questions related to the impressions and feelings about such activities; and (c) four questions with respect to general comments. Questions related to students' impressions and feelings should be ranked from 1 to 5 based on how much students agree with them (5 means that you strongly agree; 1 means that you strongly disagree).

\section{LEARNING ACTIVITIES}

- Which learning activities did you perform in SlideWiki?

\section{IMPRESSIONS AND FEELINGS}

- Do you think the proposed activities promote student participation?

- Do you think the proposed activities promote autonomous learning?

- Do you think the proposed activities promote knowledge sharing?

\section{GENERAL COMMENTS}

- Could you please indicate which issues related to the proposed activities you consider most interesting?

- Could you please provide constructive comments on the proposed activities?

- Could you please indicate questions that arose when participating in the proposed activities?

- Could you please indicate novel ideas you think could be interesting in the context of the proposed activities?

Figure 1. Survey Questions

After the completion of the proposed educational activities, we gathered students opinions and analyzed the data collected in the questionnaires.

Currently, learning activities have been performed by students in 2 of the planned subjects; while for the rest of the subjects activities are being performed in autumn.

- In the case of "Logic Programming" (Bachelor Level), 19 students performed the activity of creating questions for self-evaluation

- In the case of "Information Retrieval, Extraction and Integration" (Master Level), 10 students performed an activity focused on preparing a particular assignment. This activity can be seen as a combination among the activity of summarizing in 5 points and the activity of creating solutions for proposed exercises.

Table 2 shows the results of analyzing the data from questionnaires in "Logic Programming" (Bachelor Level), in particular the data related to the 'Impressions and Feelings' part. Data shows that students perceived positively the activity of creating questions for self-evaluation. Most of them (around $80 \%$ ) considered that this initiative promote student participation and autonomous learning as well as the knowledge sharing. According to several students "the most interesting aspect is that you can share exercises that you have performed yourself ... and your classmates can review them and try to correct them and understand them".

Table 3 shows the results of analyzing the data from questionnaires in "Information Retrieval, Extraction and Integration" (Master Level), in particular the data related to the 'Impressions and Feelings' part. In this case, data shows that students were skeptical with respect to the learning activity performed: only $40 \%$ of the students considered that this initiative promote student participation, autonomous learning as well as knowledge sharing. 
Table 2. Results in "Logic Programming"

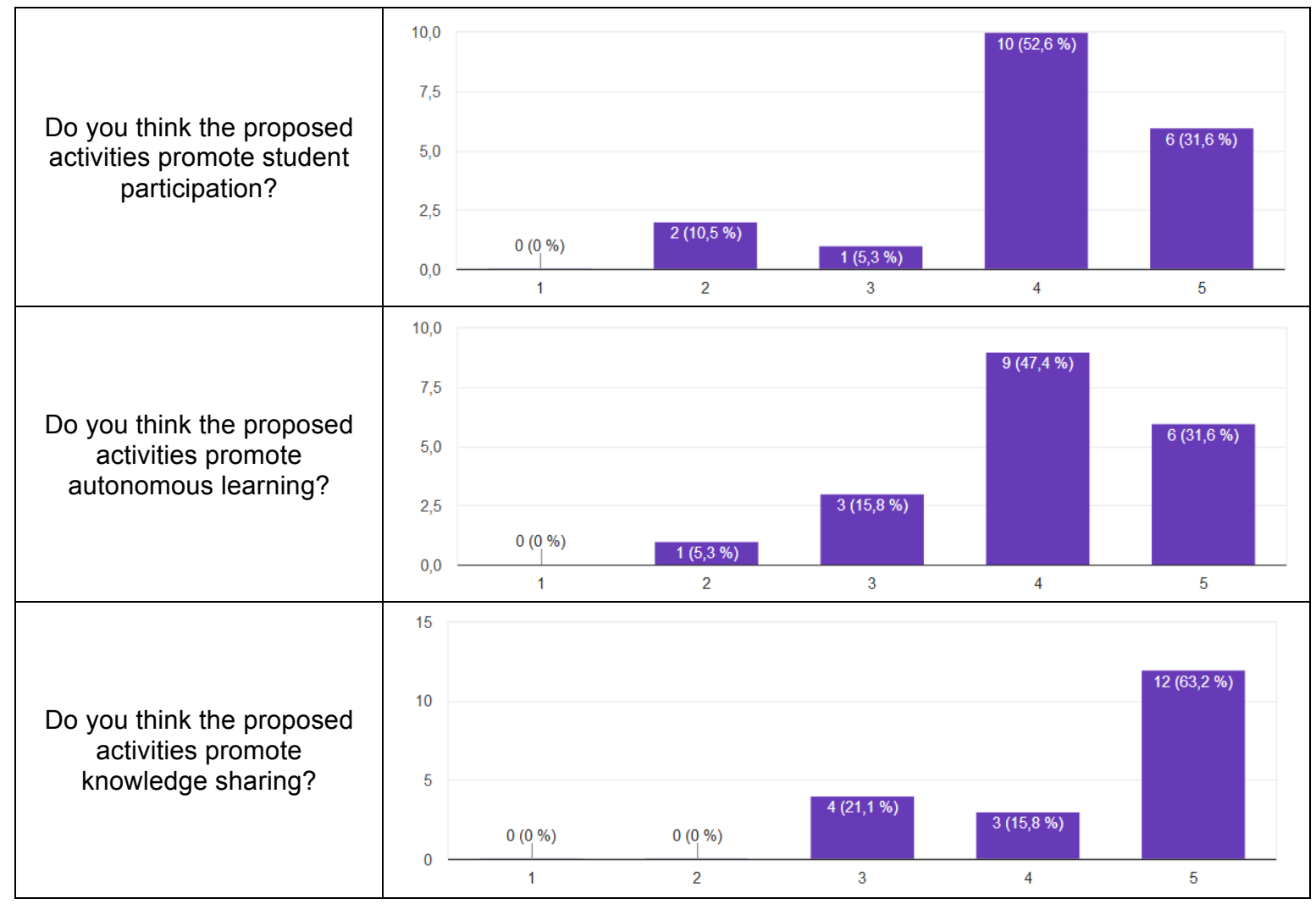

Table 3. Results in "Information Retrieval, Extraction and Integration"

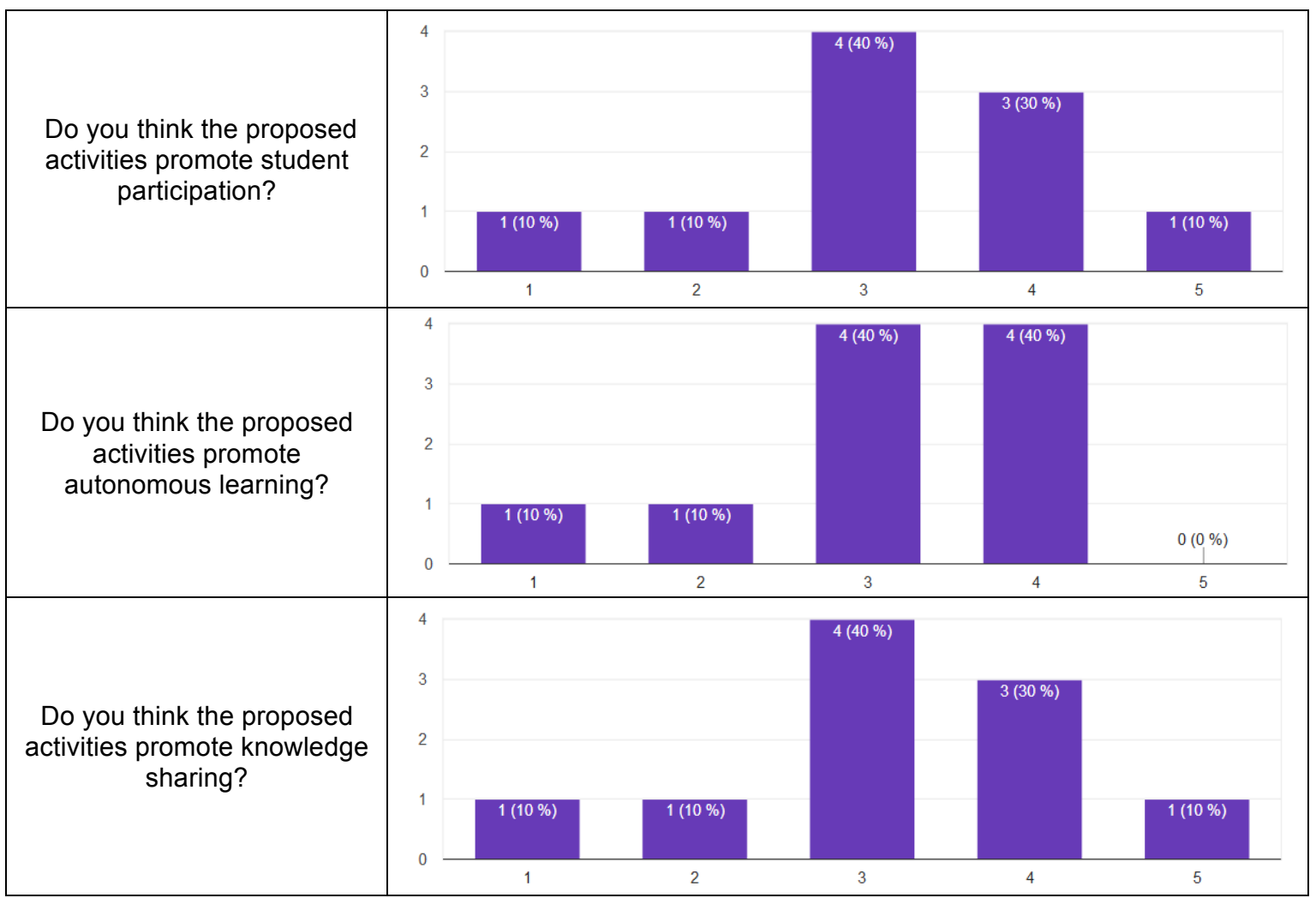




\section{CONCLUSIONS}

The crowdsourced-based approach proposed in this paper has as main objective to encourage the active participation of students in the creation and improvement of educational materials that are used in the study and/or self-learning of university disciplines. Students participate in a set of learning activities during 2017-2018 course. This active participation of students is done following a crowdsourcing approach using the SlideWiki platform. This crowdsourcing approach helps increase both the quantity and quality of educational materials in an online environment.

The involvement of students in the creation and improvement of educational materials allows (a) having much of the content expressed in a language closer to the students, as well as (b) having explanations and examples more understandable. In addition, the crowdsourced-based authoring proposal allows the development of a wide library of learning materials that can be shared and reused across the educational community.

Once all the proposed educational activities have been carried out, we will obtain a collection of teaching materials, improved and developed by students, following a crowdsourcing approach. This collection will be available in the form of slides on the SlideWiki platform, and thus available to the entire educational community.

In order to evaluate the impact of the learning activities proposed in this approach, we are compiling students opinions via questionnaires. Current preliminary data shows that the idea is perceived well by students; although some improvements need to be included specially in the case of master courses.

As future work, we are going to apply learning analytics techniques to compare opinions and results obtained in 2017-2018 course with opinions and results from previous courses. Our goal here is to check whether the application of the proposed approach has had a positive impact on students opinions and results. In addition, we are going to analyze whether the degree of active participation of students in this type of innovative educational activities is influenced by the educational level and/or the course taken by students.

\section{ACKNOWLEDGEMENTS}

This research work has received funding from the Universidad Politécnica de Madrid, thanks to the innovative educational project "Un Enfoque basado en 'Crowdsourcing' para la Creación y Mejora de Materiales Educativos", and from the EU Horizon 2020 programme under grant agreement No 688095 (SlideWiki project).

\section{REFERENCES}

[1] D. Tarasowa and S. Auer. "Collaborative Authoring of OpenCourseWare". The Best Practices and Complex Solution. Open Data for Education - Linked, Shared, and Reusable Data for Teaching and Learning. pp 103-131, 2016

[2] M. Laal, S. M. Ghodsi, "Benefits of collaborative learning". Procedia - Social and Behavioral Sciences, Volume 31, 2012, Pages 486-490, ISSN 1877-0428, https://doi.org/10.1016/j.sbspro.2011.12.091

[3] W. T. Tsai, W. Li, J. Elston and Y. Chen, "Collaborative Learning Using Wiki Web Sites for Computer Science Undergraduate Education: A Case Study," in IEEE Transactions on Education, vol. 54, no. 1, pp. 114-124, Feb. 2011. doi: 10.1109/TE.2010.2046491

[4] A. Khalili, S. Auer, D. Tarasowa, and I. Ermilov. "SlideWiki: Elicitation and Sharing of Corporate Knowledge using Presentations". Proceedings of the EKAW 2012, Springer 